\title{
El sentido social de la salvación A diez años del acuerdo luterano-católico sobre la justificación
}

\author{
Dean Brackley, \\ Centro de Reflexión Teológica, \\ San Salvador.
}

\section{Introducción}

El año 2009 ofrece una buena oportunidad para reflexionar sobre el tema de la justificación. La razón principal consiste en que se celebra el décimo aniversario de la Declaración conjunta sobre la doctrina de la justificación de la Federación Luterana Mundial y el Vaticano. Es también el año de san Pablo, proclamado por el Vaticano en 2008 y que finalizará en 2009; y como es sabido las cartas de Pablo son las que, en el Nuevo Testamento, abordan más extensamente y en mayor profundidad el tema de la justificación. Este año, finalmente, se cumple el $\mathrm{V}$ centenario del nacimiento de Juan Calvino, insigne defensor de la justificación por la fe.

La Declaración luterano-católica, promulgada el 31 de octubre de 1999, día de la Reforma, en Augsburgo, Alemania, marca un hito en la historia del cristianismo y del movimiento ecuménico. El acuerdo es fruto de un intenso diálogo en diversos lugares bajo el impulso del Concilio Vaticano II (1962-1965) y puso fin a las condenas mutuas entre luteranos y católicos en lo tocante a la justificación del pecador. Históricamente, es el tema doctrinal más importante de la reforma protestante y fue "la principal causa de la división de la Iglesia oc- 
cidental" en el s. XVI ${ }^{1}$. Algunos sectores de ambas iglesias ${ }^{2}$ mostraron reservas hacia el texto básico, la llamada "propuesta definitiva" terminada en 1997. Pero la adición, en 1999, de un "Anexo" clarificador hizo posible que el Vaticano formalizase el acuerdo con la Federación Mundial Luterana ese mismo año. Posteriormente, otras iglesias cristianas fueron aceptando el histórico acuerdo ${ }^{3}$, revitalizando un movimiento ecuménico que estaba en necesidad de nuevo impulso.

El documento declara que "las iglesias luterana y católica romana se encuentran en posición de articular una interpretación común de nuestra justificación por la gracia de Dios mediante la fe en Cristo", y que otras diferencias sobre este tema principal "ya no dan lugar a condenas doctrinales" (DC 5). Con esto no se quiere negar que "subsisten cuestiones de mayor o menor importancia que requieren ulterior aclaración, entre ellas, temas tales como: La relación entre la Palabra de Dios y la doctrina de la iglesia, eclesiología, autoridad en la iglesia, ministerio, los sacramentos y la relación entre justificación y ética social" (DC 43).

$\mathrm{Al}$ acercamiento y mutuo enriquecimiento de posturas, contribuyeron, además del impulso del Concilio, otros factores, sobre todo los avances en los estudios bíblicos y en la investigación histórica de la teología (DC 13).

En este artículo queremos reflexionar sobre la relevancia de "la justificación por la fe" en un mundo injusto, y lo haremos teniendo muy en cuenta a las víctimas de la injusticia. Al desarrollar algunos temas sociales, esperamos contribuir también a llenar algunos vacíos históricos en la explicación de la justificación y de la soteriología cristiana en general. La justificación del pecador se ha entendido casi exclusivamente como el perdón del pecado personal y como la reconciliación del individuo con Dios. Ha sido comprendida como elemento de una doctrina de la salvación, pero entendida ésta como la amistad del individuo con Dios, o como santificación del individuo en la vida presente, ciertamente como miembro de la iglesia, o como bienaventuranza en el cielo. Hay que ensanchar esta perspectiva, y ubicar la justificación del pecador en el marco más amplio de

1. Declaración conjunta, número 13. En adelante, nos referimos a la Declaración como $D C$, seguido por el número de párrafo. El texto puede consultarse en varios lugares de Internet, como el del Vaticano (http://www.vatican.va/roman_curia/pontifical_councils/chrstuni/documents/rc_pc_chrstuni_doc_31101999_cath-luth-jointdeclaration_sp.html), o en Escritura y Verdad (http://www.escriturayverdad.cl/CONFESIONES\%20DE\%20FE/Declaracion\%20Conjunta.pdf). Un buen resumen de la Declaración y su "Anexo", con análisis y contexto histórico, puede consultarse en V. M. Fernández, La gracia y la vida eterna. Dimensiones de la amistad con Dios, Barcelona, 2003, pp. 285-301.

2. La Declaración no pretende resolver diferencias sobre el término "Iglesia" (véase su nota 9).

3. En 2006 la XIX Asamblea General del Concilio Mundial Metodista, reunida en Seúl, Corea, acordó subscribir la Declaración. 
la obra salvífica de Dios en la historia, que transforma la vida social y que promete un mundo nuevo en el que habitará la justicia.

\section{La justificación por la fe}

La doctrina de la justificación por la fe es central en el cristianismo de Pablo, si no es la doctrina central. Y aunque dicha fórmula esté ausente en otras tradiciones neotestamentarias, para las tradiciones de la reforma esto vale para el Nuevo Testamento en su conjunto. Para la reforma luterana se trata del "artículo primero y principal", "director y juez de las demás doctrinas cristianas" $(D C 1)^{4}$. Sin embargo, muchos católicos desconocen la doctrina y sus implicaciones, o solo la conocen en formas simplistas y distorsionadas que ocultan su riqueza.

¿Qué significa "justificación por la fe"? En palabras de Pablo, "el ser humano es justificado por la fe, independientemente de las obras de la ley" (Rom 3, $28)^{5}$. Por la pura gracia de Dios y sin mérito alguno de nuestra parte, pasamos de ser personas culpables a personas perdonadas, reconciliadas con Dios. Es la justificación por gracia de parte de Dios; y de parte nuestra por la fe y no por obra humana alguna. Sola gratia, dijo Lutero, y sola fides. La ley (toráh) expresa la voluntad de Dios, pero las obras de la ley no consiguen el perdón de Dios. El amor no se compra, la gracia es gratuita. Si de obras se trata, la única obra que ha expiado la culpa del mundo es la obra de Jesús, su vida y sobre todo su muerte por amor. Esta es la "fe" — en el sentido de obra-de-fidelidad - de Jesús que justifica. Ninguna obra nuestra —ni penitencias, ni oraciones, ni actos de misericordia - puede merecer la gracia divina u obligar a Dios a perdonarnos. Lo que Dios exige de la humanidad pecadora es aquella fe que acoge su amor. Pide sólo fe. En eso insistió Lutero, pero fe en toda su riqueza, es decir, aquella fe que es confianza en Dios y que necesariamente "obra por el amor" (Gal 5, 6) .

El amor de Dios es el que libera de la culpa. Libera de una religión de miedo, mercantilista e infantil. Libera de la esclavitud de la ley, permitiéndonos vivir, bajo el Espíritu, la libertad de hijas e hijos de Dios. La razón para salir en procesión en semana santa o hacer penitencias, no debe ser el vano intento de

4. La primera cita está tomada de los Artículos de Esmascalda (de 1537), II, 1, y la segunda de la obra de Martín Lutero, Die Promotionsdisputation von Palladius und Tilemann (1537), WA (Edición de Weimar de las obras de Lutero), Tomo 39, I, p. 205. Se trata del articulus stantis et cadentis ecclesiae. Sobre esta expresión y la centralidad de este "artículo" para la reforma luterana, véase E. Jüngel, El evangelio de la justificación del impio como centro de la fe cristiana. Estudio teológico en perspectiva ecuménica, Salamanca, 2004, pp. 35-38.

5. Cfr. Gal 2, 16-21; 3, 10-18; 5, 1-6; Rom 3, 20 - 5, 11; 9, 30-32; 10, 3-4.9-10; Tit 3, 4-7; Ef 2, 4-10.

6. La $D C$ insiste en repetidas ocasiones en que la fe necesariamente se manifiesta en obras de amor. 
expiar por nuestros pecados. Si ayudamos al prójimo, no será para purgar por nuestros pecados y ganar crédito ante Dios, sino para responder a la dignidad humana y para introducir el bien en el mundo. Las obras buenas necesarias son la obra de Dios en nosotros. No constituyen ningún motivo para "gloriarnos" ante los demás, ni mucho menos ante Dios.

Durante siglos de polémica, la parte protestante ha enfatizado la sola fides, la sola gratia, a veces hasta descuidar las obras que la auténtica fe produce, a pesar de las claras afirmaciones de los reformadores. La parte católica, por su parte, ha insistido en la necesidad de las obras, muchas veces sin apreciar la gratuidad de la justificación, a pesar de la clara afirmación del Concilio de Trento. Aunque sea obvio, hay que insistir en las dos caras de la moneda. Lo vamos a ilustrar con la parábola de Félix y Tristana.

Félix ha traicionado a su esposa Tristana. Ella descubre el adulterio que él ha cometido con la "otra", llamémosle Rosa. Se siente destrozada. Sin embargo, con el tiempo y con mucha dificultad, Tristana decide imitar al mismo Dios y decide ofrecerle perdón a su esposo infiel, buscando así la reconciliación. Espera el momento oportuno y entonces confronta a Félix con los hechos. Éste, asustado y desorientado en un primer momento, termina aceptando que no le queda más remedio que admitir su error. Tristana se le anticipa y le ofrece perdón, sin exigirle nada por el dolor que le ha causado, y sin castigarle. A Félix le cuesta creer que no le reproche nada, pero al final lo acepta. Expresa su gratitud y admiración por la magnanimidad de su esposa. Luego, reflexiona y pregunta a Tristana: “puedo seguir con Rosa?”.

A1 llegar a este punto, el lector seguramente reaccionará con estupor. ¡Por supuesto que no puede seguir con la otra! Por gratuito que sea el perdón de Tristana, y precisamente por ello, es necesario que Félix haga algo que exprese intrínsecamente su aceptación del perdón. Se trata de arrepentirse y creer en la buena noticia de ese perdón ( $c f r$. Mc 1, 15). Lo mismo ocurre con el perdón de Dios: No hay recriminación por el pasado, pero creer implica romper con ese pasado y, con la ayuda de Dios, en adelante tomar un rumbo distinto. Significa obrar de otra manera. En el caso de Félix, aceptar el perdón implica dejar a Rosa. En el caso de quien ha robado, implica devolver lo robado y no robar más.

Si la teología protestante pone el énfasis en la gratuidad del perdón de Dios - como el que ofrece Tristana-, la teología católica lo pone en que "la fe sin obras está muerta" (St 2, 26). Al insistir en ello, no solo afirma la necesidad de las obras después de la justificación, sino también la necesidad del arrepentimiento, es decir, el cambio real de vida, como elemento esencial de la conversión.

Hay que aceptar las dos caras de la moneda. Por horribles que sean los pecados del pasado, Dios acoge como el padre del hijo pródigo. Todo queda borrado; no hay que pagar nada al padre para compensar por los errores. Sólo hay que 
acoger su perdón ("creer"). Pero elemento de ese ser acogido es la ruptura, que acaece conjuntamente con la praxis que el perdón exige intrínsecamente.

Hemos puesto como ejemplo el pecado contra un individuo. Digamos ahora una palabra sobre crímenes contra el bien de la sociedad como un todo, como puede ser el homicidio, y más aún crímenes de lesa humanidad. Son casos que conocemos de cerca en Centroamérica y que, por desgracia, siguen abundando en muchos lugares en estos tiempos de disgregación social y política.

Los delitos contra el bien común requieren procesos públicos que lleven a la reconciliación social y a la seguridad pública?. Se necesitan procesos que incluyan elementos de acusación formal, de condena, de rehabilitación y de indemnización adecuada. Nada de esto contradice la gracia de Dios, ni elimina la necesidad de perdonar. La misma gracia debe inspirar a las víctimas a imitar el perdón de Dios, por difícil que esto sea aun con la ayuda de Dios. Las víctimas más inmediatas, como familiares ofendidos, necesitan perdonar para sanar. Pero su perdón tampoco basta en caso de crímenes que dañan a la sociedad en su conjunto. Para la reconciliación y la seguridad social sigue siendo necesario que haya procesos públicos. La disposición de perdonar y el proceso público deben nutrirse mutuamente como elementos esenciales de la reconciliación social.

Las diferencias entre católicos y luteranos que hemos señalado surgen de diferentes conceptos de la fe que justifica, y de maneras diferentes de concebir la acción divina en relación con la humana. Tanto para católicos como para luteranos, la fe consiste en adherirse a Cristo, quien encarna la misericordia de Dios. Pero la teología reformada insiste en que esta fe no es obra - según Lutero, el ser humano recibe el perdón de Dios pasivamente ${ }^{8}$ - En cambio la teología católica

7. La teología luterana también reconoce esta necesidad en la vida pública, pero distingue radicalmente todo lo que tiene que ver con la autoridad pública de todo lo que tiene que ver con la gracia y la fe. Se trata de dos "reinos" completamente distintos, el reino de Dios y el reino civil. En el primero se procede por pura gracia y misericordia; en el segundo, por justicia estricta. El primero corresponde al evangelio y el segundo a la ley, y no deben mezclarse. Por eso el gran teólogo protestante Ernst Troeltsch no duda en hablar del "individualismo cristiano luterano", cuya "influencia en el mundo exterior (a la Iglesia) es nula". E. Troeltsch, The Social Teaching of the Christian Churches, vol. II, Chicago y Londres, 1976 (ed. orig., 1911), p. 540. Con el desarrollo del luteranismo, se convirtió en "principio permanente" el que "todos los asuntos seculares y políticos, y por tanto la cuestión del bienestar social, pertenecen a la provincia del Gobierno, mientras la Iglesia se preocupa solamente por la salvación del alma y la vida interior de la piedad personal" (ibid., p. 567). Hoy la mayoría de los teólogos luteranos se distancian de esta postura.

8. Cfr. DC 21. Karl-Heinz Menke considera que Lutero confundió la fórmula de Tomás de Aquino, fides caritate formata, la fe in-formada por la caridad, con su interpretación por parte de nominalistas como Guillermo de Ockham y Gabriel Biel. En esta perspectiva, la fe, la esperanza y la caridad pueden llegar a considerarse como 
considera que Dios mismo (por su gracia "preveniente") despierta en la persona una fe activa que acoge el perdón de Dios. Despierta la capacidad de colaborar en el proceso de conversión (gracia "cooperante"), lo que incluye la ruptura con el pecado (o un "firme propósito de la enmienda").

Aun después de firmarse la Declaración conjunta, siguen existiendo otras diferencias en la manera de entender la justificación. La tradición reformada, por ejemplo, insiste en que la justificación es esencialmente un cambio en la relación de la persona con Dios: es pasar de una situación de culpa nuestra y condena divina a otra situación de amistad gracias a la acogida de Dios. Se trata de una justificación forense, en el sentido de que Dios declara perdonada a la persona. Sin embargo, el indulto divino y la amistad nueva no alteran el desorden moral interno (concupiscencia) del individuo perdonado, y este desorden sigue siendo una abominación para Dios. Por tanto, el individuo perdonado sigue siendo pecador. En la frase clásica de Lutero, es simul iustus et peccator, a la vez justo y pecador.

La teología católica insiste, más que su contraparte protestante, en que la nueva relación con Dios cambia a la persona justificada. Con la justificación por la fe, celebrada en el bautismo, la concupiscencia ya no implica culpa. Además, Dios mismo (la gracia) transforma a la persona, liberando su libertad y ordenando sus amores. El Espíritu de Dios (la gracia) potencia la colaboración humana con su obra santificadora, como vimos. Aunque Juan Calvino habla más que Lutero de la santificación como proceso, la teología protestante nunca aceptó el lenguaje católico de la "gracia habitual" (en cuanto ésta sugiere algo poseído por nosotros) y el "mérito" (en cuanto sugiere algo que obliga a Dios).

Estas diferencias se basan en dos maneras diferentes de concebir a Dios en relación con el mundo, y en dos maneras de interpretar la condición del hombre pecador. La tradición reformada enfatiza la trascendencia absoluta de Dios respecto a su creación. Dios es infinitamente otro. Y además, el ser humano, como pecador, se ha apartado aún más del Dios santo. Y ello no solo considerando al ser humano puntualmente como pecador, sino desde la raíz, de tal manera que es incapaz de realizar la más mínima obra que le acerque a ese Dios. Todas sus obras, incluso las aparentemente buenas, surgen de un corazón egoísta que las vacía del más mínimo valor moral. Al ser humano sólo le queda esperar y recibir la gracia del Dios misericordioso, que le perdona y le justifica a pesar suyo y en contra de su voluntad pecaminosa.

Para la teología católica, en cambio, la encarnación de Cristo revela a un Dios que, por muy trascendente que sea, puede y quiere hacerse criatura. Este

"cualidades adquiridas que Dios [...] reconoce con su gracia como un boleto que da el acceso al cielo" (K. H. Menke, Teologia de la gracia. El criterio de ser cristiano, Salamanca, 2006, p. 147). 
hecho central revela la afinidad de Dios con su creación, especialmente con la humanidad. La tradición católica, por lo tanto, concibe la relación Dios-creación a partir de una imaginación analógica9. Considera, además, que el "pecado" original y la concupiscencia no dejan a las personas en un estado tal que Dios sea incapaz de suscitar su colaboración en la conversión y en su obra salvífica en general.

A pesar de sus diferencias históricas, las dos Iglesias han podido llegar a un acuerdo fundamental sobre la justificación. Entre los varios factores que lo han facilitado, sospecho que ha sido clave una nueva comprensión, por parte y parte, del papel específico del Espíritu Santo en la salvación y en la justificación en $\operatorname{particular}^{10}$. A diferencia de las tradiciones de Oriente, en las iglesias cristianas de Occidente, tanto la católica romana como las reformadas, el papel específico del Espíritu divino ha estado opacado, desde el tiempo de Agustín, debido al énfasis tradicional en la unicidad de Dios y en la obra conjunta de las tres "personas" divinas. Los avances en el estudio bíblico y dogmático han facilitado comprender mejor la obra del Espíritu divino en la reconciliación del pecador, y esto ha facilitado un acercamiento de posturas de las Iglesias sobre la obra de Dios en nosotros.

\section{Ampliando el horizonte}

No es posible ahora profundizar más en estos temas, ya que nuestro interés principal es otro: ampliar la perspectiva para desarrollar el sentido social de la justificación, y de la salvación en general. Por trascendente que sea el acuerdo histórico entre católicos y luteranos, la Declaración conjunta todavía se mantiene dentro de un horizonte reducido, común a las dos tradiciones, donde no queda claro qué significa la buena noticia de la justificación y de la salvación para las personas y para los pueblos que más sufren la mala noticia del pecado del mundo actual.

Es comprensible que el enfoque de la Declaración se concentrara en lo que dio lugar a las divisiones históricas que pretendió sanar. Superar las diferencias entre las interpretaciones clásicas de cada tradición ya era una tarea compleja y difícil en sí. Intentar ir más allá hubiera resultado más difícil todavía. Sin embargo, como veremos, la Declaración, sin excusa razonable, se queda corta al

9. D. Tracy, The Analogical Imagination: Christian Theology and the Culture of Pluralism, Nueva York, 1981.

10. Cfr. las reflexiones de James Dunn sobre el papel del Espíritu Santo y "participación en Cristo" como elementos clave en la regeneración de las personas justificadas según Pablo (J. D. G. Dunn, The New Perspective on Paul [Revised Edition], Grand Rapids, 2008, pp. 82-95; e ibíd., Cap. 22, "Philippians 3, 2-14 and the New Perspective on Paul", pp. 469-490). 
no preguntarse por el sentido social de la salvación, con el riesgo de mantener una interpretación individualista, ahistórica y espiritualista de la obra salvífica de Dios. La Declaración, en efecto, deja la impresión de haberse conformado con la privatización de la salvación que ha ensombrecido a la teología cristiana desde los tiempos patrísticos. Para el propósito de este artículo dejamos ahora de lado las razones por esta estrechez de miras. Solo insistimos en que la salvación proclamada en el Nuevo Testamento - incluyendo las cartas de Pablo- es algo más que el perdón de los pecados. Para ampliar la perspectiva sobre la misma justificación y para ubicarla en un marco más amplio de la salvación, desarrollaremos tres puntos.

Primero, sacaremos las implicaciones sociales de la misma doctrina de la justificación, siguiendo las líneas maestras de lo que hoy se llama la "nueva perspectiva" sobre Pablo y sus implicaciones para el mundo actual. Segundo, mostraremos cómo la justificación del impío en Pablo se puede ubicar en un marco más amplio de la obra salvífica de Dios en Cristo, que no se limita a la justificación en esta vida y a la vida eterna en el más allá. Tercero, para ilustrar el sentido social de la gracia examinaremos la proclamación del reinado de Dios en los evangelios sinópticos. Una breve investigación de la "justicia" y el "juicio" de Dios en el Antiguo Testamento servirá de puente entre el segundo y el tercer punto, descubriendo las raíces comunes de la justicia de Dios en Pablo y el reino de Dios en la proclamación de Jesús.

\section{La nueva perspectiva sobre Pablo}

En las últimas décadas se ha desarrollado entre los exégetas una "nueva perspectiva" sobre la teología de las cartas de Pablo" ${ }^{11}$. Dentro de una pluralidad de posturas en esa corriente, es posible hablar de un consenso que cuestiona ciertas estrecheces de la interpretación de Pablo en la tradición agustiniana y en la luterana. No se pone en duda la justificación por la gracia y la sola fe, pero sí se redescubren dimensiones hasta hoy desatendidas. En general, se trata de ampliar y complementar las "viejas perspectivas" más que de anularlas ${ }^{12}$.

La "nueva perspectiva" parte de una intuición de E. P. Sanders, cuyas investigaciones han demostrado que en el judaísmo del Segundo Templo (del fin del exilio hasta el primer siglo de nuestra época) la toráh y sus obras no se oponían

11. Véanse J. Dunn, The New Perspective on Paul, óp. cit., passim; y K. H. Menke, Teología de la gracia, óp. cit., cap. 6, "La investigación reciente como revisión radical de la exégesis agustiniana de Pablo", ambas obras con amplia bibliografía.

12. Si bien la nueva perspectiva convalida la tesis de la justificación por la sola fe, cuestiona la tradición agustiniana-luterana de interpretación de Pablo respecto a la ley y la libertad humana. Cfr. K. H. Menke, Teología de la gracia, óp. cit. 
a la gracia de Dios ${ }^{13}$. Según el Deuteronomio, el libro clave para comprender la alianza en este período, la toráh es un gran don de Dios a Israel. No se cumple la toráh para ser aceptado por Dios, o para ganar su perdón, menos aún para incorporarse a su pueblo, sino para mantenerse como amigo de Dios, miembro de su pueblo y heredero de sus promesas. Uno goza de esta pertenencia y amistad por pura iniciativa divina; pero para permanecer en ese estado, es necesario cumplir los mandamientos (cuando no se cumplen, hay que recurrir a los medios de expiación de pecado). En este esquema la gracia no se opone a la ley y las obras que exige. Gracia y obras son inseparables para lo que Sanders ha llamado el "nomismo de la alianza" (covenant nomism). En esto "Pablo coincide con el judaismo palestino", escribe Sanders; "[...] la salvación es por la gracia, pero el juicio es según las obras; las obras son condición para seguir 'en', pero no se gana la salvación por ellas" 14 .

Esta perspectiva modifica la antítesis luterana entre ley y evangelio, como oposición entre obras y gracia. La Declaración conjunta no prestó suficiente atención a este punto. Al afirmar la justificación por la pura fe, Pablo no se opone a judíos que creen haberse ganado la gracia divina por sus obras. El apóstol insiste en la justificación gratuita ante judíos que quieren imponer la circuncisión y las normas de dieta ("obras de la ley") para cristianos gentiles, obligándolos a vivir como judíos. En Gálatas Pablo responde con vehemencia que los gentiles no tienen que vivir como judíos; pues de ser así Cristo murió en vano. Ahora, gracias al amor-hasta-la cruz de Jesús el mesías, Dios acepta gratuitamente a quienes creen en Cristo, tal y como Dios había elegido gratuitamente a Israel. Por otra parte, para mantenerse en el nuevo pueblo de Dios ya ampliado, los cristianos gentiles tienen que vivir conforme a la voluntad de Dios, cumpliendo los justos preceptos de la ley (Rom 8,4 ; $c f$ ICo 7,19$)$ que se resumen en el amor al prójimo.

La "nueva perspectiva" afirma, por una parte, la doctrina de la justificación por la (sola) fe; pero por otra, rechaza una oposición entre fe y obras, o entre gracia y ley, como tales. Pablo no polemiza contra la ley, sino contra el mal uso de la ley, sea por presumir de la gracia de Dios por el mero hecho de ser judíos, sea por confiar en obras y méritos propios, sea por exigir a los paganos que vivan como judíos.

Sin embargo, para nuestro propósito nos interesan más las implicaciones sociales del nuevo paradigma: Pablo afirmó la justificación por la fe, sin las obras de

13. Cfr. E. P. Sanders, Paul and Palestinian Judaism: A Comparison of Patterns of Religion, Londres, 1977. Las intuiciones de Krister Stendahl ("The Apostle Paul and the Introspective Conscience of the West", Harvard Theological Review 65 [1963], pp. 199-215) anticiparon el cambio de paradigma en la manera de entender a Pablo.

14. E. P. Sanders, Paul and Palestinian Judaism,óp. cit., p. 543. 
1a ley, "en gran parte si no principalmente" ${ }^{15}$ para indicar que la acción salvífica de Dios en Cristo ha destruido la barrera entre judíos y gentiles (cfr. Ef 2, 1416), una barrera simbolizada por exigencias como la circuncisión y las normas dietéticas, que marcaban la frontera entre el pueblo judío y otras naciones. Para ser salvados, los gentiles no tienen que hacerse judíos. La salvación es para todos los y las que creen (Rom 10,4). En versiones de luteranismo, como en la lectura existencialista de R. Bultmann, por ejemplo, y en la gran mayoría de casos de evangelismo fundamentalista y pentecostal de hoy, se entiende la justificación exclusivamente en términos de la relación del individuo con Dios. La "nueva perspectiva", sin embargo, muestra, en Pablo, dimensiones sociales importantes. La postura de Pablo respecto a la justificación responde a la cuestión de cómo los gentiles pueden reconciliarse con Dios, ser parte de su pueblo y así salvarse. Para resolver este problema era crucial la actitud de los judíos, sobre todo los judíos cristianos. Los adversarios del evangelio en Gálatas y Romanos son aquellos que se jactan de ser judíos con sus prerrogativas (cfr. Rom 2, $17-20 ; 3,27 ; 9,4-5)$, despreciando a los gentiles hasta anular el amor universal de Dios y de su voluntad universal de salvación. Pablo responde que Dios no distingue ya entre judío y griego; acepta a toda persona que cree en Cristo. Pues "una vez llegada la fe, [...] ya no hay judío ni griego" (Ga 3, 25.28).

El principio sigue siendo válido también hoy. Ahora ya no importa la raza o la nación. No es necesario adoptar la cultura occidental para ser discípulo de Cristo. Imponerla en nombre de la fe es traicionar el evangelio de la justificación por la fe. Toda la diversidad de la familia humana es aceptada en la mesa del banquete mesiánico. Quedan prohibidos la discriminación y el desprecio. James Dunn argumenta que las creencias secundarias y las prácticas religiosas no esenciales pueden hacer hoy las veces de la circuncisión y las normas dietéticas. Ofrece como ejemplos de tradiciones que sirven hoy para dividir y excluir las siguientes: la infalibilidad literal de la Escritura, el creacionismo, la infalibilidad papal, la observancia del sábado, la primacía masculina, definiciones particulares de sucesión apostólica, la exclusión de la eucaristía, la exclusión de mujeres del ministerio ${ }^{16}$.

Estas creencias pueden ser verosímiles, o no. Dunn argumenta que son secundarias comparadas con la verdad primordial del amor universal de Dios que la Iglesia cristiana debe manifestar. Y en igualdad de condiciones para todo creyente y, más allá de la comunidad de fe, para toda persona y cultura. Los hipernacionalismos y mucha intolerancia religiosa deben ceder ante el criterio mayor de la inclusión. La necesidad de resistir el relativismo postmoderno y de afirmar la identidad de confesiones no justifica el riesgo de anular el amor universal de

15. J. Dunn, The New Perspective on Paul, óp. cit., p. 16.

16. Cfr. ibid., pp. 70, 96. 
Dios. Esta prioridad de principios debe estimularnos a repensar los criterios al uso para excluir a personas de la mesa eucarística, impulsar el diálogo ecuménico e interreligioso, defender los derechos de las minorías y superar los conflictos entre pueblos.

Es más. Si Dios quiere acoger y abrazar a toda la humanidad, ¿cómo es que hemos configurado el mundo de tal manera que la mayoría de personas, y países enteros, quedan excluidos de los frutos de la tierra y de la mesa donde se decide sobre su destino ${ }^{17}$ ? Y ¿qué decimos de la sociedad de consumo que "coloniza" nuestras vidas, comunicando sin cesar el mensaje de "cuanto tienes tanto vales"? Si Dios nos acepta tal y como somos con todas nuestras limitaciones, muy distinto es el mensaje con el que nos bombardea la propaganda comercial. En la sociedad tradicional hubo jerarquía social, pero las personas eran conscientes de su dignidad - de campesino, de madre - aun cuando ocupaban lugares tenidos por humildes en la pirámide social. Tenían un lugar digno y cumplían una función digna en el universo de Dios. En cambio, en la sociedad moderna, sobre todo la capitalista con su movilidad social, nos identificamos menos con nuestro empleo y profesión, que pueden cambiar de un día para otro; pensamos menos en términos de vocación. En estas circunstancias resulta más difícil consolidar la identidad, sobre todo en el ambiente urbano donde con frecuencia falta el apoyo familiar que protege el sentido del propio valor. En este ámbito la persona es más vulnerable ante el rechazo y el desprecio, más susceptible a la manipulación por mensajes subliminales como el de "si no te vistes de marca, vales menos". A su vez, la economía neoliberal excluye a la mayoría de la población (en Centroamérica, por ejemplo) de una participación digna en la vida social. El mensaje constante es "No cuentas", "No sirves", "No te necesitamos", sobre todo cuando se niega la oportunidad de educarse y formarse. Y los medios de comunicación bombardean con imágenes de jóvenes guapos y modelos rubios, que terminan despreciando a la mayoría que no lucen así. En fin, el mensaje de una sociedad configurada alrededor de la ganancia privada, de la competencia y el consumo sin freno, es de desprecio, si no de rechazo: no eres aceptable. Tienes que hacer y comprar mucho más para ser quien debes y lograr ser aceptable.

El mensaje del evangelio es todo lo contrario: Dios nos acepta. Nos quiere tal y como somos, tal y como él nos creó - seamos pobre, mujer, moreno, gorda, bajito, narizón, heterosexual u homosexual, o como el galán de la película-. Nos acepta con nuestros pecados pasados y defectos morales actuales. Y si Dios nos acepta, ¿quién nos rechazará? ¿Quién nos despreciará? El problema es de quien rechaza y desprecia. $\mathrm{Y}$ es pecado. $\mathrm{Y}$ es pecado más grande, la exclusión y

17. En estas reflexiones me inspiran las intuiciones de Elsa Támez. Cfr. E. Támez, “Justificación", en C. Floristán y J. J. Tamayo (eds.), Conceptos fundamentales del cristianismo, Madrid, 1993, pp. 664-675; más ampliamente, ídem, Contra toda condena. La justificación por la fe desde los excluidos, San José, 1991. 
el desprecio estructurales de las mayorías en nuestros países y de países enteros en la comunidad internacional.

\section{Justicia de Dios y salvación en Pablo}

Nuestras reflexiones han puesto de manifiesto las implicaciones sociales de la doctrina de la justificación. Pero para Pablo la obra salvífica de Dios no se limita a la justificación del pecador.

En las cartas paulinas el verbo dikaiōo (justificar) y los sustantivos dikaiōsis ${ }^{18}$ (justificación) y dikaiosunē (también justificación, cuando es atribuida a personas reconciliadas con Dios) ${ }^{19}$ deben entenderse en el sentido forense: Dios, el juez de los últimos tiempos inaugurados por el mesías, declara sin culpa (dikaios) al pecador. Dios lo acepta como parte de su pueblo, ampliado ahora para incluir a gentiles.

Por otra parte, no cualquier uso de estas palabras se limita al sentido forense, y la misma justificación debe entenderse como parte de una obra divina más amplia. En la versión Septuaginta $(\mathrm{LXX})$ del Antiguo Testamento, dikaioō y dikaiosune suelen traducir palabras basadas en la raíz $t s d q$, cuyo primer sentido no es legal, aunque la LXX las traduce con palabras que, en griego, tienen ese matiz $^{20}$. En Pablo ese matiz está presente y, como acabamos de ver, predomina cuando se trata de la justificación de pecadores. Sin embargo, dikaiosune, que suele traducir $t s e d e q \mathrm{y} t s^{e}$ daqah en los LXX, no pierde el sentido más rico y amplio de estas palabras hebreas. Esto vale también para Pablo, que cita la LXX al desarrollar su doctrina de la salvación en Cristo. Tsedeq y $t s^{e} d a q a h$, cuyos sentidos no son idénticos ${ }^{21}$, se refieren a la rectitud o justicia, pero van mucho más

18. Sólo aparece en Rom 4, 25 y 5, 18.

19. Como, por ejemplo, Rom 9, 30; Flp 3, 9, y con frecuencia en Rom 4 y 5; cfr. 1Co 1 , 30; 2Co 5, 21. Estos ejemplos reflejan posiblemente el sentido de salvación-liberación ( $s^{e}$ daqah) como don recibido. Cfr. E. Berkovits, Man and God: Studies in Biblical Theology, Detroit, 1969, pp. 297-305.

20. La LXX a veces acentúa el sentido jurídico, comparado con el texto hebreo. Cfr. K. Kertlege, "dikaióō", en H. Balz y G. Schneider (eds.), Exegetical Dictionary of the New Testament, vol. I, Grand Rapids, 1990, p. 331. Recuérdese cómo en la LXX diathêke (testamento) traduce $b^{e}$ rith (alianza), y nomos (ley) traduce toráh (instrucción).

21. Véase el importante ensayo "Sedeq and S'daqah", de E Berkovits, óp. cit., pp. 292348. "Hay que dudar si, entre las muchas ideas de la Biblia hebrea, existen otras que han sufrido más por malentendido, y con frecuencia por distorsión interesada, que los conceptos sedeq y s'daqah" (ibid., p. 340). Para Berkovits, tsedeq es más abstracto; significa el bien que Dios quiere; siempre busca (re)establecer relaciones, y así proteger, promover vida, liberar de peligros y de opresión. $T s^{e}$ daqah es acción liberadora, defensora de la vida. Según Moshe Weinfield, "En general, tsedeq se refiere al principio abstracto de justicia, mientras $t s^{e}$ daqah se refiere al acto concreto". "En contraste" con $t s e d e q, " t s^{e}$ daqah tiene que ver con las acciones (véase Isa 56,$1 ; 58,2$; 
allá de lo forense e incluso más allá del concepto occidental de justicia como conformidad a normas o ideales abstractos. La justicia bíblica ( $t s d q$, $m s h p t$, etc.) (re)establece relaciones con Dios, con los demás y con la naturaleza, conforme a la voluntad amorosa de Yahvé. Como es sabido, tsedeq y tsedaqah (al igual que mishpat, que se suele traducir como "juicio" o "derecho") guardan estricta y estrecha relación con jesed (misericordia, amor), emeth y emunah (fidelidad, constancia), rajamim (compasión, ternura) y $y^{e}$ shu'ah (liberación) ${ }^{22}$. Se trata de dar vida, de protegerla, de defender y liberar de peligros a los pobres, las víctimas y demás grupos vulnerables como huérfanos, viudas y extranjeros. Tsedeq y $t s^{e}$ daqah significan hacer el bien en general; pero en la Biblia hacer el bien significa promover la vida en el sentido integral, en el contexto de relaciones. Significa realizar shalom ${ }^{23}$. Esto es precisamente la obra de Dios, la única obra divina. Es lo que significa "justicia de Dios". Dios realiza esta justicia dando vida y combatiendo el pecado que trae muerte.

Pablo anuncia la buena noticia de que con Cristo, ha llegado el momento decisivo, cuando este proyecto de vida vence al pecado y la muerte (Rom $5,12-14 ; 6$, 16.21; etc.). Anuncia precisamente la "justicia de Dios" (Rom 1, 14; 3, 21; 10, 3$)^{24}$. Aquí dikaiosune traduce $t s^{e}$ daqah, acción liberadora y misericordiosa. Lo que Dios ha hecho es enviar a su hijo, que, siendo justo, murió por pecadores, tanto judíos como gentiles. Dios mostró "su justicia en el tiempo presente para ser justo y justificador del que cree en Jesús" (Rom 3, 26; cfr. 5, 8; 8, 3). Este acto de Dios no realiza justicia distributiva ni, al menos principalmente, retributiva, sino justicia salvífica; genera vida plena. Dios perdona a quienes creen en Jesús y los acepta como parte de su pueblo ya ampliado. Pero la obra no queda ahí. La

“'asa ts'daqah', "hizo $t s^{e} d a q a h '$, i. e., actuó con justicia)" (M. Weinfield, “'Justice and Righteousness'-mshpt wetsdqh-. The Expression and Its Meaning”, pp. 228-246, cita de p. 236; en H. G. Reventlow y Y. Hoffman [eds.], Justice and Righteousness: Biblical Themes and Their Influence, Sheffield, 1992). Para más bibliografía sobre la distinción entre $t s e d e q$ y $t s^{e}$ daqah, véanse las referencias $i b i d .$, p. 236, n. 1.

22. Cfr. Sal 36, 10-11; 40, 10-11; 85, 11-14; 88, 12-13; 89, 15; 98, 2-3; 103, 17; 111, 3-8; 119, 40; Os 2, 21; Mi 6, 8; Za 7, 9; y muchos ejemplos más. Examinaremos algunos más adelante.

23. "El viejo debate sobre si el sentido básico de la raíz $s d q$ es 'conformidad a la norma' o 'cumplimiento mutuo de reclamos que corresponden a una relación determinada' puede evitarse si aceptamos que la 'norma' de que se trata consiste en las demandas que surgen de la relación de Dios con su pueblo en la alianza" (D. Moo, Romans, Grand Rapids, 1996, pp. 79-80; citado en J. Dunn, The New Perspective on Paul, óp. cit., p. 64, n. 254).

24. La "justicia de Dios" no se refiere a alguna rectitud que la persona recibe de Dios (por muy extendida que esté esta interpretación). Significa "el acto salvífico de Dios como intervención salvadora suya para crear algo nuevo en el contexto del desastre de la historia humana dominada por el poder del pecado" (K. Kertlege, "dikaiosune", en Exegetical Dictionary of the New Testament, óp. cit., p. 331). 
justificación lleva a la vida integral y eterna, que es salvación en el sentido pleno (cfr. Rom 5, 17-18.21; 6, 4-8.22-23; ICo 15, 22). "Pues el salario del pecado es la muerte; pero el don de Dios, la vida eterna" (Rom 6, 23). Quienes creen en Cristo se salvarán de la "ira" (Rom 5, 9; cfr 1, 18; 11, 19). La "ira" se refiere a las consecuencias del pecado (hamartia) que ha reinado en el mundo desde Adán hasta Cristo. Entregarse al dominio del pecado trae "muerte". Pablo espera, pronto, el juicio final que introducirá la victoria de Dios y su mesías, cuando Dios será todo en todo (ICo 15, 23-28). Quienes creen como Abraham compartirán la gloria divina (Rom 5,2 ). No solo reciben perdón; no solo vivirán para siempre. Resucitarán para heredar el mundo (Rom 4, 13) que ahora gime como en situación de parto (Rom 8, 21-22). La salvación, como vida plena, significa humanidad nueva y creación nueva. Los comienzos de esta realidad se viven en las comunidades cristianas, el nuevo pueblo de Dios. La justificación significa incorporación en este pueblo nuevo, que es la vanguardia - como diríamos hoy- del mundo nuevo por nacer ${ }^{25}$.

La Declaración conjunta no habla de esta salvación integral. Más bien puede dar la impresión de que "justicia" en la Biblia se limita al perdón de los pecados y la santificación del individuo. Pero esta impresión es falsa. Si el enfoque limitado de la Declaración es legítimo, entonces es distorsionador. Al referirse a la "justicia de Dios" ocultaría sus dimensiones sociales intrínsecas.

\section{La justicia y el juicio de Dios en el Antiguo Testamento}

La Declaración luterana-católica reconoce las raíces de la doctrina de la justificación en el Antiguo Testamento, refiriéndose explícitamente a la "justicia" de Dios en Isaías 46, 13; 51, 5-8; 56, 1, y Jeremías 9, 24; y al "juicio" de Dios en Eclesiastés 12, 14; Salmos 9, 5-6 y 76,7-9 (DC 8) ${ }^{26}$. La selección de los textos es representativa y atinada. Es ampliamente reconocido, por ejemplo, que la salvación y la justicia de Dios en el Nuevo Testamento evocan los Oráculos de Consolación de Isaías y los Salmos ${ }^{27}$. En los tiempos de Jesús y de Pablo, textos como estos alimentaban las expectativas de quienes anhelaban la intervención definitiva de Dios, lo que el Nuevo Testamento proclama como realizado en Je-

25. Comprender "la justificación como el acto de Dios que reivindica una comunidad de la alianza también excluye el error individualista de tratar la justificación como la experiencia personal del creyente de perdón y liberación de una experiencia subjetiva de culpa" (R. B. Hays, "Justification", en The Anchor Bible Dictionary, vol. III, Nueva York, 1993, p. 1132).

26. Aquí corregimos errores menores de la versión de la Declaración en castellano a la luz de las versiones alemana inglesa.

27. "En deutero-Isaías la justicia de Yahvé se convierte en la expresión comprehensiva para la anticipada venida de salvación (Is 45, 8; 46, 13; 51, 5.6.8)". K. Kertlege, "dikaiosúne", en Exegetical Dictionary of the New Testament, óp. cit., p. 331. 
sús. Sin embargo, habrá que preguntar hasta qué punto los textos aducidos confirman lo que la Declaración parece decir sobre la justicia de Dios; o, dicho de otra manera, habrá que cuestionar hasta qué punto la Declaración hace justicia a los textos aducidos en apoyo a su exposición de la doctrina de la justificación. Examinemos, primero, los textos que aluden a la "justicia" ( $t s^{e}$ daqah) de Dios y luego los que aluden al "juicio" (mishpat) de Dios.

\subsection{La "justicia" de Dios}

El primer texto aducido por la Declaración, Isaías 46, 13, identifica la justicia de Dios con la liberación del pueblo desterrado:

Yo hago acercarse mi (obra de) justicia ( $t s^{e}$ daqah), no está lejos,

Y mi liberación ( $\left.t^{e} s h u^{\prime} a h\right)$ no tardará,

Pondré liberación ( $t^{e}$ shu'ah) en Sión,

mi prez será para Israel. ${ }^{28}$

El profeta emplea el paralelismo explicativo: "liberación" explica lo que es la obra de justicia divina. La liberación de los judíos exiliados y su repatriación es obra de Yahvé y de Ciro, su instrumento. Es un acto plenamente político, pero no menos religioso por ello; y viceversa. (Mientras que nuestra palabra "liberar" tiene un sentido más secular y "salvar" un sentido más religioso, estas palabras traducen ideas hebreas completamente ajenas a la distinción secular-religioso.)

En segundo lugar, veamos Isaías 51, 5-8. En el v. 4 que precede, Yahvé anuncia su "juicio (mishpat) para luz de las naciones". Luego leemos:

Inminente, cercana está mi justicia (tsedeq),

saldrá mi liberación (yesha'),

y mis brazos juzgarán a los pueblos.

$[\ldots]$

¡Como el cielo cual humo se disipa,

y la tierra cual ropa se desgasta;

sus moradores como mosquitos mueren!

Pero mi salvación ( $y^{e}$ shu'ah) para siempre será, mi obra de justicia $\left(t s^{e}\right.$ daqah) no se frustrará.

Oíganme, sabedores de lo justo (tsedeq),

pueblo consciente de mi ley.

No teman afrenta humana,

ni de sus ultrajes se acobarden.

Pues como un vestido se los comerá la polilla,

y como lana los comerá la tiña.

28. Al identificar las palabras hebreas, ignoramos la alteración de formas por sufijos y prefijos. 
Pero mi obra de justicia (ts ${ }^{e}$ daqah) por siempre será,

y mi salvación ( $y^{e}$ shu'ah) por generaciones de generaciones.

El "juicio" de Dios (v. 4) es su decisión de realizar "justicia", y esta justicia es "liberación". El resto del oráculo repite cómo la obra justa de Yahvé es la de salvar, liberar. El tercer texto aducido por la Declaración como ilustrativa de la "justicia” divina es Isaías 56, 1, que reza:

Así dice Yahvé:

Velen por lo recto (mishpat)

y practiquen la justicia ( $\left.t s^{e} d a q a h\right)$,

que mi liberación (yeshua') está para llegar

y mi obra de justicia ( $t s^{e}$ daqah) para manifestarse.

Una vez más, el paralelismo explicativo deja ver cómo el "juicio" de Dios es su decisión de hacer una justicia, que es liberación. En el mismo sentido (y el mismo contexto), cfr. Isaías 45, 8: "Derramen, nubes, tsedeq. Ábrase la tierra y produzca yesha', y germine juntamente $t s^{e} d a q a h$. Yo, Yahvé, lo he creado". Cfr. también Is 61,$10 ; 62,1-2$.

Finalmente, como ejemplo de lo que es la "justicia" de Dios, la Declaración aduce Jeremías 9, 24: "[...] yo soy Yahvé, que hago misericordia (jesed), lo recto (mishpat) y justicia ( $t s^{e}$ daqah) sobre la tierra". Lo más probable es que mishpat-tsedaqah debe interpretarse como hendíadys: Yahvé hace misericordia y justicia salvífica. (Nótese la misma hendíadys en forma de paralelismo en Is 56, 1a, que acabamos de comentar).

Muchos otros textos ilustran que la "justicia de Dios" significa su acción misericordiosa y liberadora ${ }^{29}$; tiene poco o nada de matiz jurídico. Citemos solo tres ejemplos más. Según el salmo 22, se contará la tsedaqah de Yahvé (v. 32), que libera al justo "mísero" de sus adversarios (v. 25) y a los hambrientos (v. 27). El salmo 31, 1 (2) reza, "En ti, Yahvé, me cobijo, [...] ¡Recóbrame por tu tsedaqah, [...] líbrame". El salmo 71, 2 identifica la $t s^{e}$ daqah de Yahvé con su acción salvífica, liberadora (vv. 2 y 15) y con sus proezas y poderío (vv. 16 y 18).

En resumen, aunque la Declaración se refiere a la "justicia de Dios" en el Antiguo Testamento como aporte para comprender la justificación forense del pecador, en los textos aducidos, que sí son representativos, esta "justicia" se refiere a acciones de misericordia de Dios, que liberan a pobres y afligidos de sus apuros y sus opresores.

29. Véanse Sal 103, 17; 143, 1.11-12; 145, 7-8. Varios textos hablan de "las obras de justicia de Dios" ( $t$ sidqoth, pl. de $t s^{e} d a q a h$ ): Jue 5, 11; 1Sam 12, 7; Sal 103, 6; Mi 6, 5; Dan 9, 16. 


\subsection{El "juicio" de Dios}

En el Nuevo Testamento la justificación de los impíos anticipa el juicio final y la victoria definitiva de Dios sobre el pecado y la muerte. Ya dijimos que la Declaración aduce Eclesiastés 12, 14; Salmos 9, 5-6; y 76, 7-9 como textosfuentes del "juicio" justo de Dios. A diferencia de lo que acabamos de ver en el caso de la "justicia de Dios", aquí nos encontramos en el ámbito jurídico. Sin embargo, al examinar estos textos, veremos que el "juicio" divino no debe entenderse estrechamente como una decisión imparcial según normas abstractas; ni se limita al ámbito legal.

El primer ejemplo proviene del último versículo del libro de Eclesiastés (Qohelet): "[...] Dios traerá toda obra a juicio (mishpat), también todo lo oculto, a ver si es bueno o malo" $(12,14)$. Aunque el versículo es totalmente claro, es muy general. Quedando al final del epílogo añadido posteriormente al libro, su contexto da poca información sobre el juicio divino y sus criterios. Los textos del salterio lo explican en mayor detalle.

En el segundo ejemplo del juicio justo de Dios, salmo 9, 5-6, leemos:

Pues defendiste mi causa (mishpat) y mi juicio (din),

sentado en tu sede como justo juez (shōphet tsedeq).

Expulsaste a los gentiles, destruiste al malvado,

borraste su nombre para siempre jamás.

La Declaración se refiere a la palabra mishpat, traducida aquí como "causa", que proviene de la misma raíz que shaphat, juzgar, y shōphet, juez. El texto continúa, indicando en qué consiste el juicio/mishpat de Dios:

Yahvé [...] establece para el juicio (mishpat) su trono:

Él juzga al orbe con justicia (tsedeq),

sentencia a los pueblos con rectitud (meshārim).

¡Sea Yahvé un baluarte para el oprimido,

baluarte en tiempos de angustia [...]!

no desoye el grito angustiado de los desdichados.

[…]

No quedará olvidado el pobre para siempre,

La esperanza de los desdichados nunca se frustrará.

¡Levántate, Yahvé, no triunfe el hombre,

Sean juzgadas las naciones en tu presencia! (vv. 8-9.13.19-20.)

El contexto esclarece que el juicio y la justicia del Rey divino consisten en defender y rescatar a pobres y oprimidos.

El salmo 10, que es muy posiblemente la segunda mitad del salmo 9, continúa en la misma línea, especificando cuáles son los juicios del justo Rey divino: el malvado codicioso y prepotente desprecia los juicios (mishpatim) de Yahvé, 
mientras triunfa en base a fraude y doblez $(10,2-7)$. Espía, atrapa y asesina al desdichado inocente (vv. 8-11). Por todo ello, el salmista grita indignado: “ ¡Álzate, Yahvé, extiende tu mano! ¡Nunca te olvides de los desdichados! [...] el desvalido en ti se abandona, tú eres el auxilio del huérfano. [...] ¡Yahvé es rey por siempre, por los siglos; han sido barridas las naciones de su tierra! El deseo de los humildes tú escuchas, Yahvé, confortas su corazón, les prestas atención, para hacer justicia (shaphat) al huérfano, al vejado" (vv. 12-18).

En su forma actual, el salterio ha sido organizado en gran parte según los temas tratados y sus formas literarias (sean salmos de alabanza, de lamento, etc.). El contexto de Salmos 9-10 confirma que los mishpatim de Yahvé, el Rey justo, son juicios en contra de opresores y perseguidores y en defensa de "pobres" y "justos"30.

Como tercer ejemplo ilustrativo del "juicio" de Dios, la Declaración aduce el salmo 76, 7-9 (8-10), que reza así:

Tú eres terrible, ¿quién puede resistir

ante ti, bajo el golpe de tu ira?

Desde el cielo pronuncias la sentencia (din),

la tierra se amedrenta y enmudece

cuando Dios se levanta a juzgar (mishpat),

a salvar (yäsha') a todos los humildes de la tierra.

En lugar de "la tierra" puede traducirse "el país": Dios se levanta a salvar a la gente pobre del país (Israel) del agresor foráneo (cfr. vv. 1-6). El sentido de mishpat queda suficientemente claro en este himno, un cántico de Sión, y es confirmado, además, en el contexto más amplio del salterio. El salmo que precede celebra las hazañas de Yahvé que juzga con rectitud $(75,3)$ y reprocha a los arrogantes (vv. 5-6). "Dios, como juez, a uno abate y a otro exalta" (v. 8). Ambos salmos forman parte de la antigua colección "de Asaf", salmos 73 a 83. Casi todos estos $(74-77 ; 79-80 ; 83)$ celebran —o solicitan - la acción liberadora de Yahvé en defensa de su pueblo abatido por sus enemigos poderosos.

En resumen, los salmos 9 y 76, con sus contextos, nos hablan del mishpat liberador y misericordioso de Dios. En el mismo sentido, el salmo 72 reza "Oh, Dios, da al rey tu mishpat, al hijo de reyes tu $t s^{e}$ daqah..." (v. 1); "Él hará justicia (shaphat) a los humildes del pueblo, salvará a los hijos de los pobres, y aplastará al opresor" (v. 4).

30. Los salmos 3 a 17, de la primera serie "davídica", son todos ellos oraciones de confiada súplica frente a enemigos y la adversidad, siendo los salmos 8 y 14 excepciones. Mientras los salmos 7,9 y 10 explícitamente identifican a Yahvé como juez justo y los salmos 9-10;12;14 lo identifican como defensor de los pobres, los demás salmos en esta serie suponen esta teología. 
Estos textos, y muchos otros ${ }^{31}$, confirman que, cuando Dios "juzga" (shaphat), como "juez" (shōphet) y realiza "lo justo" (mishpat), efectúa una justicia que salva, que reivindica a la víctima y que, por tanto, es justiciera contra el opresor. Se trata de una dimensión de aquella divina "justicia" amorosa y salvadora que es tsedeq, que defiende y promueve la vida amenazada por la muerte y reestablece las relaciones injustas o rotas ${ }^{32}$. Porque Dios juzga así, no hay contradicción entre su justicia (mishpat) y su misericordia (jesed). En el salmo 119, 149.156 leemos "Por tu amor (jesed), Yahvé, escucha mi voz; dame vida conforme a tus mishpatim. [...] Grande es tu ternura, Yahvé; dame vida conforme a tus mishpatim".

Este recorrido pone de manifiesto que la justicia de Dios y el juicio de Dios se refieren a su acción, por puro amor y compasión, para liberar a quienes sufren - a pobres, huérfanos y marginados y al pueblo perseguido- de peligros, de la opresión y de la muerte. Si Pablo apela a esta justicia (dikaiosune) de Dios en el contexto del juicio (mishpat/krisis) escatológico del mundo, por mucho que enfatiza el perdón gratuito y la aceptación de pecadores, proclama esta justificación como parte de la obra salvífica de Dios más amplia. La Declaración reconoce de dónde provienen estos conceptos centrales para el evangelio que Pablo proclama, pero no dice nada del sentido más amplio de la salvación, sentido que debe afectar la interpretación de la justificación misma. Se comprende que los autores de la Declaración no pretendieron elaborar un tratado sobre la salvación en todas sus dimensiones. Su empeño era otro. Pero al no mencionar nada de esta obra salvífica más amplia, pueden dar la impresión de que la salvación se limita al perdón de pecados, la regeneración del individuo y la vida eterna después de la muerte. Cuando se refieren a las raíces veterotestamentarias de la justicia de Dios sin mayor elucidación, pueden dar la impresión de que consideran que la $t^{e}$ daqah y el mishpat de Dios, que se refieren a la liberación de oprimidos, han sido "espiritualizados" en el Nuevo Testamento; que la obra de Dios en el Antiguo Testamento, que trae bendiciones materiales y políticas, y las promesas "utópicas" de los profetas, han sido superadas en el Nuevo Testamento por bendiciones exclusivamente "espirituales." En esta interpretación, el intérprete cristiano "alegoriza" sin más el significado social de la acción de Dios en el éxodo y "espiritualiza" su defensa de las víctimas en las demás tradiciones y las promesas de los profetas de una sociedad justa y fraterna. Ciertamente hay novedad en el Nuevo Testamento. Pero no es ésa la novedad. La indebida "platonización" y la constricción de la obra salvífica de Dios han plagado la historia del cristianismo. Una lectura adecuada de los evangelios muestra que en ellos se anuncian buenas noticias para pobres y víctimas. Pablo también lo comprendió así.

31. Cfr. los siguientes textos que se refieren a Yahvé: Dt 10, 11; Sal 9, 9; 33, 5; 35, 23 24; 36, 6-11; 67, 5; 82; 94; 98; 101, 1; 146, 7-9; Is 5, 15-16; 30, 18; 61, 8; Os 2, 21.

32. Véanse E. Berkovits, "The Biblical Meaning of Justice", en Man and God, óp. cit.; y

M. Weinfield, "Justice and Righteousness", óp. cit. 


\section{La salvación como reino de Dios}

Jesús anuncia la "justicia de Dios" para los últimos tiempos, para la era nueva. Se trata nada menos que de la llegada del Rey de Dios en poder. La nueva realidad de este reinado divino comienza con su ministerio, aunque su plena realización queda en el futuro. El cuarto evangelio enfatiza la actualidad del reinado, del juicio y de la vida eterna ( $c f r$. Jn 4,$23 ; 5,25$; etc.).

Terminamos nuestra reflexión examinando este mensaje de Jesús para relacionarlo con la justificación de los pecadores. Como veremos, una comprensión correcta de la "justicia" ( $t s^{e}$ daqah) de Dios y su "juicio" liberador (mishpat) ayuda mucho poner en relación estos dos temas y a situar la justificación de los impíos en un marco adecuado.

Para hablar de la obra salvífica de Dios, Jesús elige la fórmula "reinado de Dios", que apenas aparece en el Antiguo Testamento, aunque la idea de Dios-rey sí es común. Se trata de un símbolo ineludiblemente sociopolítico. Jesús anuncia un "cambio de régimen" universal: Dios se está encargando del mundo. ¿Qué significa y qué implica esto? Para saberlo, son claves las declaraciones programáticas al respecto. Textos como el discurso inaugural de Jesús en Nazaret (Lc 4), las bienaventuranzas (Lc 6), la respuesta de Jesús a los emisarios de Juan el Bautista (Lc 7 y Mt 11), el Magníficat de María (Lc 1), etc., manifiestan que la llegada del reino es buena noticia para los pobres y afligidos (y mala noticia para los ricos y hartos). Las bienaventuranzas de Lucas pueden servir aquí para ilustrar los puntos fundamentales y su relación con el tema de la justificación.

Como todos estos textos programáticos, las bienaventuranzas evocan los Oráculos de Consolación de Isaías 40-66 que proclaman liberación para grupos de pobres que aguantan hambre y están afligidos (Is 61, 1-7; 49, 10.13; 65, 13 14; etc. $)^{33}$. Tanto en el contexto de Lucas como en los Oráculos queda claro que no nos encontramos ante una pobreza espiritual - ni ante un hambre espiritual ni lágrimas espirituales - sino ante víctimas cuyo sufrimiento clama al cielo. Las bienaventuranzas anuncian la respuesta del Rey divino. Su reinado se fundamenta en la justicia, lo recto y la misericordia fiel - en $t$ sedeq, mishpat, jesed $w^{e}$ emeth (cfr. Sal 89, 15; 97, 2; 99, 4; 146 passim, que caracterizan el reinado divino) - . Estas palabras se refieren precisamente a la rectificación de relaciones sociales rotas y torcidas y el establecimiento de shalom. Así actúa el Rey divino en defensa de los débiles, como así debe de actuar cualquier rey (cfr. Sal 72 , 1-4.7.12-14; 82; Sab 1, 1; Jer 22, 1-5; etc.). Las cualidades del rey justo, cuya figura es extendida en las culturas del antiguo Oriente Medio, fundamentan la

33. Seguimos aquí la interpretación, ampliamente aceptada, de Jacques Dupont sobre las bienaventuranzas. Cfr. J. Dupont, Les Béatitudes, vol. 2: La bonne nouvelle, París, 1969. 
esperanza en el mesías, el vicario de Yahvé ( $c f r$. Is $11,1-5)^{34}$. Jesús proclama que Dios viene precisamente como rey justo para cumplir las promesas de los profetas, liberando a los pobres. Estos dejarán de sufrir hambre y de llorar. Estarán de fiesta como en un banquete (Mt 8, 11; 22, 1-10; Lc 12, 37).

Esta interpretación del reino de Dios suscita preguntas importantes. ¿Cómo encaja con el resto del mensaje del evangelio? Y ¿cómo encaja con la justificación del impío? En especial, ¿se trata de quitar "trascendentalidad" al reino de Dios, reduciéndolo a abundancia material, a pan (cfr. Mt 4, 3-4)? A esta última pregunta hay que responder que, en la Biblia, la pobreza - sufrida por la gran mayoría en Galilea en tiempos de Jesús - no consiste en primer lugar en la carencia de bienes, sino en la opresión y la marginación. Éstas producen carencia, pero cuando se habla de miseria, se trata en primer lugar de una relación social. "Pobres" incluye a toda la gente excluida y marginada, sobre todo (como primer analogado) los grupos económicamente oprimidos. La teofanía de Rey divino cambia relaciones sociales injustas y establece relaciones justas, de solidaridad. Este es el punto de las "desgracias" en Lucas: ay de ustedes, ricos, hartos, que se ríen.

¿Se trata de condenar la risa y la satisfacción? Tampoco. Se trata de denunciar y llamar a conversión a quienes, como el "rico epulón", ignoran a los Lázaros que languidecen ante sus puertas. El problema de los ricos no es sólo o principalmente su "apego" a las riquezas, sino la manera en que éstas des-apegan al rico de su prójimo en necesidad, apartándolo así de Dios y su reino. Este reino - acción salvífica y liberadora de Dios - acaba con las relaciones injustas a favor de relaciones justas y solidarias (tsedeq, mishpat, shalom).

Entonces, ¿odia Dios a los ricos? Las desgracias de Lucas 6 y las demás denuncias no significan eso. Dios, ciertamente, advierte a los ricos de "la ira" por venir: ¡que se conviertan y acepten la propuesta de Dios! Pero el Padre de Jesús no odia a nadie. Habrá que dudar, incluso, si ama más a los pobres ${ }^{35}$. Lo que sí es cierto es que Dios se pone de parte de las víctimas de la opresión. ¿Por qué? ¿Hay algo meritorio en ser pobre? ¿Son más virtuosos los pobres? Las bienaventuranzas (y demás textos programáticos) no dicen nada en ese sentido. En la Biblia no hay nada meritorio en la pobreza como tal. El Dios de la vida combate la miseria y la opresión. Pero no lo hace porque los pobres sean santos. Sin duda,

34. Leemos en Juan que el reinado del mesías Jesús "no proviene de este mundo" violento y mentiroso (Jn 18,36), sino de "arriba" (In 8,23), ya que es un reino de verdad y amor. El enviado sólo hace lo que su Padre quiere y hace; en el hijo enviado vemos la obra del Padre (cfr. 14, 10).

35. Me parece cuestionable la expresión "amor preferencial por los pobres", no así "opción preferencial". Es más que cuestionable que Dios ama más a pobres y mujeres que a ricos y varones. Lo que queda fuera de duda es que Dios toma partido de las víctimas de la injusticia, porque así es Dios; Él actúa a favor de ellas, y sus verdugos tendrán que responder a Él. 
algunas víctimas serán más virtuosas que sus verdugos. Pero estos temas son ajenos a las bienaventuranzas y demás textos que anuncian buenas noticias a los pobres. Los textos hablan en primer lugar de Dios. No hablan de las actitudes y acciones de las víctimas (o de los discípulos de Jesús, como en las bienaventuranzas de Mateo). Hablan de las actitudes y las acciones de Dios, que toma partido por las víctimas. No lo hace porque son buenas, sino porque Dios es bueno y misericordioso y porque las víctimas sufren, y sufren injustamente. Dios no tolera la opresión de los débiles. El punto no es que los pobres optan por Dios, sino que Dios opta por ellos. No se trata de méritos o de virtudes de ellos; se trata de la gracia de Dios, en el sentido estricto y puro. El Dios de Jesús se porta como una madre que observa cómo su hijo mayor abusa de su hermano menor. La madre se pone de parte de la víctima (¡aunque sea un malcriado!). Como madre buena, ama a ambos hijos, pero corre a defender al que necesita ayuda.

¿Qué diremos de pobres egoístas e incrédulos, que no faltan, ni faltaban en tiempos de Jesús? ¿Será el reinado de Dios para ellos, sin más? La pregunta provoca una respuesta casi automática: Dios toma partido por pobres y víctimas sólo porque Dios es misericordioso; pero recibir el don de nuevas relaciones sociales requiere una respuesta humana. Requiere conversión. Lo podremos ilustrar con otra parábola: Si Dios se pone de parte del obrero oprimido en la fábrica, por pura bondad divina, se pone de parte de la mujer del mismo obrero cuando éste llega a casa y abusa de ella. Dios opta por la víctima en cada caso. Al reproducir la opresión en su hogar, el obrero rechaza en la práctica la liberación del reino que Dios le ofrece. No cree.

Si bien esta proclamación de Jesús era revolucionaria y provocadora, cualquier judío contemporáneo con un conocimiento medio de la toráh y los profetas hubiera comprendido el mensaje; hubiera esperado que Dios actuara así. Resultó mucho más sorprendente y escandalosa, sin duda, la otra opción de Dios que Jesús anunció y puso en práctica: la opción por los pecadores. ¿Quién hubiera anticipado aquello de que "los publicanos y las prostitutas llegan antes que ustedes (líderes religiosos) al reinado de Dios” (Mt 21, 31)? ¿Quién hubiera pensado que el mesías Jesús se acercara a los pecadores despreciados - los acoge, dice Jon Sobrino - portando el perdón de Dios, incluso antes de arrepentirse, o pedir perdón (Lc 15; Mc 2, 15-17; Jn 8, 11)? ¿Por qué opta Dios así por los pecadores? Obviamente, no por sus méritos o sus actitudes. Una vez más, aquí no se trata de la bondad de los beneficiarios, sino de la bondad y las actitudes de Dios. El perdón es gratis, es gracia. En una sociedad judía dividida entre ricos y pobres por una parte y "justos" y pecadores por otra, Dios opta por los despreciados y marginados, para incluirlos en la comunidad nueva. Se trata de relaciones sociales nuevas. La compasión de Jesús y su Padre por la gente marginada y despreciada - que incluía a pecadores, mujeres, leprosos, endemoniados, niños (despreciados en la antiguiedad), samaritanos, etc. - es la clave para comprender su mensaje. Jesús acoge a todos y todas en una comunidad nueva, el nuevo pue- 
blo de Dios. Es un mensaje del amor compasivo (jesed) que se manifiesta en esa acción liberadora ( $t s^{e}$ daqah) que llamamos "reinado de Dios".

La acogida y perdón de los pecadores en los evangelios corresponde a la justificación de los impíos en Pablo - por pura gracia, independientemente de las obras de la toráh-. Pero la buena noticia anunciada en los evangelios y en las cartas de Pablo significa más que perdón. La salvación es más que la justificación del individuo. Es el reino que Jesús anunció. Es la justicia de Dios que Pablo anunció. Y esto significa personas nuevas, reconciliadas con Dios, en comunión entre sí en relaciones nuevas. Significa vida integral y eterna, un mundo nuevo "donde habita la justicia" (2Pe 3,13$)$.

En la comunidad de los discípulos de Jesús y las comunidades fundadas por Pablo, vemos las primicias de este reino. Jesús pone en práctica su mensaje, manifestando la gracia y acogida de Dios a toda clase de personas despreciadas. Esperando la llegada del Día del Señor, Pablo se esfuerza en anunciar la buena noticia a los gentiles y esperar que los judíos también se avergüencen y acepten a Jesús. Pero su preocupación es allanar el camino para que esos gentiles acepten la buena nueva. A ellos sobre todo hay que anunciar la justificación "independientemente de la toráh" (Rom 3,21) y sus obras (Rom 2, 28). Pero el evangelio no es sólo el perdón del impío por pura gracia; es también liberación del pobre - por pura gracia-.

\section{Conclusión}

La Declaración conjunta sobre la doctrina de la justificación marca un hito en la historia del cristianismo. Su décimo aniversario es motivo de acción de gracias y estímulo para seguir trabajando para sanar las divisiones que permanecen entre las iglesias cristianas "para que todos sean uno".

Debe movernos a sacar las implicaciones de la justificación por la sola gracia, repensando las exclusiones que opacan el amor universal de Dios. La acogida universal de Dios debe motivarnos a combatir toda forma de discriminación basada en raza, género, nacionalidad y la exclusión masiva de pobres de la mesa de la creación y la mesa de las decisiones.

Como vimos, la obra salvífica de Dios tampoco se limita a la justificación y la santificación del pecador, más la inmortalidad del alma. Su obra de justicia misericordiosa, realizada en Cristo, lleva a la vida plena. Es perdón y regeneración de la persona; es liberación de la miseria y la opresión, relaciones justas y solidarias, comunidad nueva; es resurrección y mundo nuevo. La opción gratuita de Dios en favor de pecadores va de la mano con su opción en favor de pobres y víctimas. Es la misma gracia que perdona y libera de la miseria. Es el amor de Dios que produce vida en abundancia, transformando el mundo roto por el pecado en creación nueva. 